\title{
Technical note: Rapid image-based field methods improve the quantification of termite mound structures and greenhouse-gas fluxes
}

\author{
Philipp A. Nauer ${ }^{1}$, Eleonora Chiri ${ }^{1,2}$, David de Souza ${ }^{3}$, Lindsay B. Hutley ${ }^{2}$, and Stefan K. Arndt ${ }^{1}$ \\ ${ }^{1}$ School of Ecosystem and Forest Sciences, The University of Melbourne, 500 Yarra Boulevard, \\ Richmond, Victoria 3121, Australia \\ ${ }^{2}$ Research Institute of the Environment and Livelihoods, Charles Darwin University, Ellengowan Drive, \\ Casuarina, Northern Territory 0810, Australia \\ ${ }^{3}$ Darwin Medical Imaging, Jape Homemaker Village, 356 Bagot Road, Millner, Northern Territory 0810, Australia
}

Correspondence: Philipp A. Nauer (pnauer@unimelb.edu.au)

Received: 24 January 2018 - Discussion started: 2 March 2018

Revised: 17 May 2018 - Accepted: 3 June 2018 - Published: 20 June 2018

\begin{abstract}
Termite mounds (TMs) mediate biogeochemical processes with global relevance, such as turnover of the important greenhouse gas methane $\left(\mathrm{CH}_{4}\right)$. However, the complex internal and external morphology of TMs impede an accurate quantitative description. Here we present two novel field methods, photogrammetry (PG) and cross-sectional image analysis, to quantify TM external and internal mound structure of 29 TMs of three termite species. Photogrammetry was used to measure epigeal volume $\left(V_{\mathrm{E}}\right)$, surface area $\left(A_{\mathrm{E}}\right)$ and mound basal area $\left(A_{\mathrm{B}}\right)$ by reconstructing 3-D models from digital photographs, and compared against a waterdisplacement method and the conventional approach of approximating TMs by simple geometric shapes. To describe TM internal structure, we introduce TM macro- and microporosity $\left(\theta_{\mathbf{M}}\right.$ and $\left.\theta_{\mu}\right)$, the volume fractions of macroscopic chambers, and microscopic pores in the wall material, respectively. Macro-porosity was estimated using image analysis of single TM cross sections, and compared against full Xray computer tomography (CT) scans of $17 \mathrm{TMs}$. For these TMs we present complete pore fractions to assess speciesspecific differences in internal structure. The PG method yielded $V_{\mathrm{E}}$ nearly identical to a water-displacement method, while approximation of TMs by simple geometric shapes led to errors of 4-200\%. Likewise, using PG substantially improved the accuracy of $\mathrm{CH}_{4}$ emission estimates by $10-50 \%$. Comprehensive CT scanning revealed that investigated TMs have species-specific ranges of $\theta_{\mathrm{M}}$ and $\theta_{\mu}$, but similar total porosity. Image analysis of single TM cross sections pro-
\end{abstract}

duced good estimates of $\theta_{\mathbf{M}}$ for species with thick walls and evenly distributed chambers. The new image-based methods allow rapid and accurate quantitative characterisation of TMs to answer ecological, physiological and biogeochemical questions. The PG method should be applied when measuring greenhouse-gas emissions from TMs to avoid large errors from inadequate shape approximations.

\section{Introduction}

Termite mounds (TMs) are among nature's most impressive structures. The aboveground (epigeal) extensions of generally belowground (hypogeal) termite nests are orders of magnitude larger than the termites themselves, and their variety in size, shape, structure and complexity is unique among eusocial insects (Korb, 2011; Noirot and Darlington, 2000). Mounds consist of solid but porous walls made from soil and termite faeces that provide protection against the environment, and a complex network of internal chambers that harbour the termite colony and serve as conduits for gas transport or as food storage (Korb, 2011; Schmidt et al., 2014). Mound architectures are highly specific for each termite species; they represent unique solutions to the problem of efficiently combining contrasting functions vital for the colony's survival, such as exchange of respiratory gases vs. homeostasis (King et al., 2015; Korb and Linsenmair, 1999; 


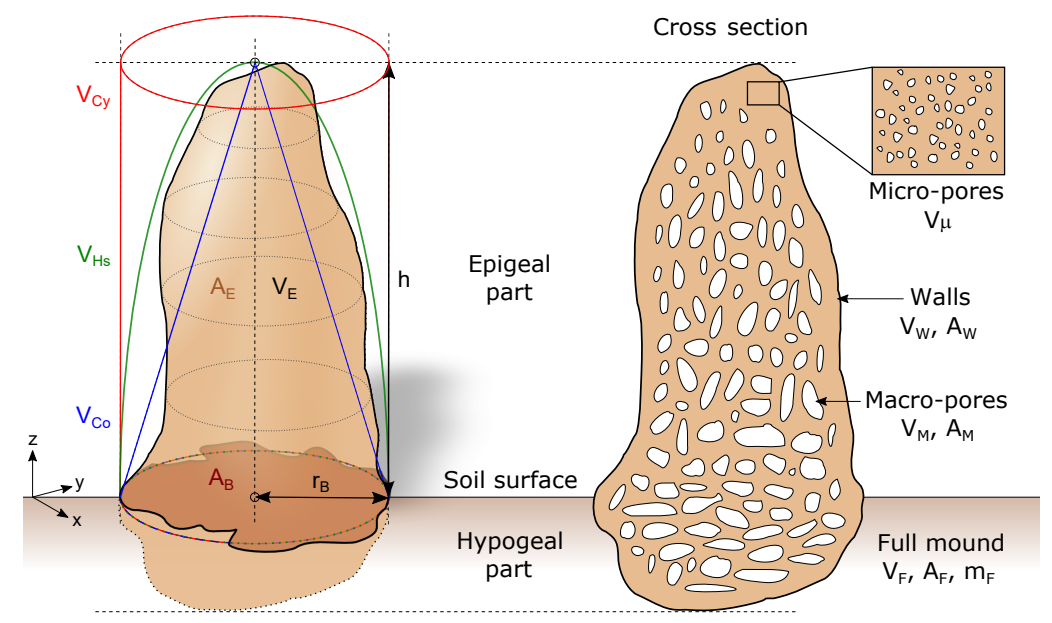

Figure 1. Illustration of external and internal surface and volume fractions of a termite mound (TM). $V_{\mathrm{E}}$ : epigeal volume; $A_{\mathrm{E}}$; epigeal surface area; $A_{\mathrm{B}}$; basal area (intersection of the TM with the soil surface); $r_{\mathrm{B}}$ : radius of a hypothetical circle with a circumference equal to $A_{\mathrm{B}}$; $h$ : epigeal height; $V_{\mathrm{Cy}}, V_{\mathrm{Hs}}, V_{\mathrm{Co}}$ : volume of a hypothetical cylinder, hemi-spheroid and cone, respectively, used to approximate $V_{\mathrm{E}}$ based on $r_{\mathrm{B}}$ and $h ; V_{\mu}$ : volume of micro-pores in the wall material; $V_{\mathrm{W}}$ : volume of the wall material; $A_{\mathrm{W}}$ : area of wall material in a cross section; $V_{\mathrm{M}}$ : volume of macro-pores (all cavities large enough for termites; generally referred to as "chambers"); $A_{\mathrm{M}}$ : area of macro-pores in a cross section; $V_{\mathrm{F}}$ : full mound volume including all pores and hypogeal parts; $A_{\mathrm{F}}$ : area of the full mound in a cross section; $m_{\mathrm{F}}$ : mass of the full mound.

Turner, 2001; Zachariah et al., 2017). Yet, due to their opaque and complex nature, the morphology and structure of TMs are inherently difficult to quantify, and there is a lack of methods to adequately determine even basic physical parameters such as epigeal volume $V_{\mathrm{E}}$ and surface area $A_{\mathrm{E}}$ (Fig. 1).

The external dimensions of a TM and precise estimates of $V_{\mathrm{E}}$ and $A_{\mathrm{E}}$ are critical for termite ecology, physiology and biogeochemistry. Data on TM size are the basis for the assessment of regional termite abundance via TM population estimates (e.g. Darlington, 1990; Darlington and Dransfield, 1987). Also, termite populations of individual TMs can be estimated by counting all termites in a sub-sample with known volume, then upscaling with $V_{\mathrm{E}}$ (Jones et al., 2005). For termite physiology, there is a need to determine the epigeal surface area $A_{\mathrm{E}}$ through which respiratory gases are exchanged with the atmosphere (Fig. 1). It has been hypothesised that respiratory gas exchange of a termite colony directly regulates TM architecture (Korb and Linsenmair, 1999), and models have been proposed to estimate TM population via TM size (Josens and Soki, 2010). Likewise, accurate estimates of TM volume and area are crucial for termite biogeochemistry: both parameters contribute directly to the calculation of gas-flux estimates from chamber-based methods (e.g. Jamali et al., 2011; Seiler et al., 1984), as do measurement errors therein. This is relevant on a global scale, as termites are a significant source of the greenhouse gas methane $\left(\mathrm{CH}_{4}\right)$ to the atmosphere, but estimates of the source strength remain highly uncertain (Kirschke et al., 2013; Saunois et al., 2016). Yet, in studies reporting gas fluxes from TMs, descriptions of TM physical parameters are often a mere side note, and sometimes omitted altogether.
The conventional approach to determine $V_{\mathrm{E}}$ has been to measure height, diameter or circumference of the TMs, then approximate the overall shape by simple geometries such as cone, cylinder or spheroid (Jamali et al., 2011; Jones et al., 2005; Josens and Soki, 2010). This may work reasonably well for small and relatively simple TMs, but may also result in large discrepancies for complex morphologies, e.g. mounds with several chimneys, large bases or buttresses. An accurate but often impractical approach is the complete dismantling and sectioning of a TM and subsequent volume measurement by water displacement, which is destructive and laborious (Holt et al., 1980). A more elegant approach for $V_{\mathrm{E}}$ was described by Seiler et al. (1984), who determined headspace volume by injecting known amounts of $\mathrm{CH}_{4}$ into the chamber and measuring its dilution. However, this approach avoided estimating basal area $\left(A_{\mathrm{B}}\right.$; Fig. 1$)$ by reporting fluxes "per mound", which led to large variability caused by different TM sizes; an issue also arising when scaling fluxes based on chamber basal area (Khalil et al., 1990), or a standardised projected area (Brümmer et al., 2009).

Photogrammetry (PG) via digital surface reconstruction is a relatively new low-cost approach to documenting and measuring complex three-dimensional structures in nature. For example, PG has been embraced by the archaeological community for the documentation of cultural heritage sites (De Reu et al., 2013), used to measure the bulk density of soil clods (Stewart et al., 2012), to measure shapes and dimensions of aquatic organisms (Lavy et al., 2015), and to determine the diameter and biomass of buttressed and irregularly shaped tropical tree trunks (Bauwens et al., 2017). However, this approach has not been applied on TMs; therefore, there 
is currently no accurate, reliable, non-invasive method to determine the critical external physical parameters of TMs such as $V_{\mathrm{E}}, A_{\mathrm{E}}$ and $A_{\mathrm{B}}$.

Similarly, due to a lack of easily applicable methods there is little quantitative information on the internal structure of TMs. However, such information is needed to quantify and compare biogeochemical processes within the mound material, e.g. microbial respiration or $\mathrm{CH}_{4}$ oxidation in TMs (Holt, 1998; Sugimoto et al., 1998). Investigations into internal structures were typically based on cross-sectioning TMs with hand tools in the field (e.g. Kandasami et al., 2016; Turner, 2001), or filling the internal chambers with gypsum ("endocasting"; King et al., 2015; Turner and Soar, 2008), which are largely descriptive and quite laborious methods. To our knowledge, a quantitative interpretation of cross sections has not been attempted.

Recently, researchers have applied medical imaging techniques such as X-ray computer tomography (CT scanning) to characterise TMs' internal structures (Perna et al., 2008; Perna and Theraulaz, 2017). This revealed not only the full internal structure and chambers' connectivity, but allowed the construction of models for a mechanistic understanding of termites' mound-building behaviour (Eom et al., 2015). While this methodology is powerful and non-invasive, CT scanning requires expensive equipment that may not be readily available for non-medical applications. Furthermore, the size of TMs to be investigated is limited by the capacity of the scanner.

However, a complete 3-D reconstruction may not be required to gain physically relevant information on internal structure. Like soil, a TM can be described as porous media, and thus simple concepts such as porosity and pore-size distribution can be applied (Luxmoore, 1981). We may define the macro-porosity $\theta_{\mathrm{M}, \mathrm{V}}$ of a TM as $V_{\mathrm{M}} / V_{\mathrm{F}}$ in Fig. 1, the volume fraction of all chambers and tunnels large enough to host termites (and thus visible to the human eye); the microporosity $\theta_{\mu}$ as $V_{\mu} / V_{\mathrm{F}}$ in Fig. 1, the volume fraction of microscopic pores within the wall material; and the total porosity $\theta_{\mathrm{t}}$ as the sum of $\theta_{\mathbf{M}}$ and $\theta_{\mu}$, the volume fraction of all pore space within the TM. Such a framework may not only provide essential information for quantifying transport of gases, water and energy through the TM, but also reveal physically relevant structural variations between TMs of different species. However, besides CT scanning there is currently no simple method to quantify internal volume fractions and thus porosities in TMs.

Here we describe two readily applicable field methods to quantify physical and morphological parameters of TMs: (i) a PG method based on structure-from-motion (SfM) reconstruction from digital photographs, to determine epigeal volume, surface area and morphological parameters, and (ii) an image-analysis method based on painted cross sections to determine internal volumes, porosities and structural parameters. We compare the methods with previous approaches to quantify termite mound characteristics, including
CT scanning, on three north Australian termite species with different mound architectures. In an example application, we illustrate potential errors in $\mathrm{CH}_{4}$ flux measurements when relying on approximate geometric shapes. Our results demonstrate the feasibility, accuracy and limitations of the novel methods for characterising TMs of different termite species.

\section{Materials and methods}

\subsection{Field sites and termite species}

All field measurements and TM sampling were performed in a coastal savanna woodland on the campus of Charles Darwin University in Darwin, Northern Territory, Australia $\left(12.370^{\circ} \mathrm{S}, 130.867^{\circ} \mathrm{E}\right)$. The site was dominated by Eucalyptus tetrodonta and Eucalyptus miniata species over an understory of annual and perennial tropical grasses, and it experiences a frequency of fire of approximately 1 in 5 years. The soil type was a Brown Kandosol typical for the greater Darwin area, with textures of loamy sand to sandy loam (McKenzie et al., 2004). Termite mounds in a sub-area of approximately 3.5 ha were counted and mapped after a fire in August 2015; the areal density of TMs was approximately 50-60 TMs ha ${ }^{-1}$. We selected $29 \mathrm{TMs}$ of various sizes from the three most frequent mound-building termite species in this area: Microcerotermes nervosus (Hill) (Mn), Macrognathotermes sunteri (Hill) (Ms) and Tumulitermes pastinator (Hill) (Tp). The TMs are named with their species' abbreviation and numbered from smallest to largest $V_{\mathrm{E}}$ (Table $\mathrm{S} 1$ in the Supplement).

All field measurements and sampling were conducted in April and May 2016. The photogrammetric method was employed on undisturbed TMs to determine $V_{\mathrm{E}}, A_{\mathrm{E}}$ and $A_{\mathrm{B}}$ of all 29 investigated TMs, including large ones with a $V_{\mathrm{E}}>30 \mathrm{~L}$. For comparison with conventional estimates, basal circumference and height of the TMs was determined manually. On $20 \mathrm{TMs}$ of small $\left(V_{\mathrm{E}}<15 \mathrm{~L}\right)$ to medium $\left(V_{\mathrm{E}}<30 \mathrm{~L}\right)$ volume, we performed measurements of gas flux between the TM and the atmosphere. A total of 17 of these TMs were then selected for excavation, CT scanning and cross-sectioning. Termite mounds were carefully excavated with hand tools by digging from the previously marked basal perimeter downwards. Most mounds had a relatively clear outer boundary to the soil, i.e. the wall material was distinct from soil in texture and density. However, some TMs of $M$. sunteri, a soil-interface feeder, featured extended basal areas with relatively soft hypogeal parts. Greater care was required for this species, and some peripheral parts had to be discarded as they were too soft for transportation. Thus, the epigeal ratio of $M$. sunteri mounds may be slightly overestimated. After excavation, TMs were weighted in the field, then transported to the lab for further processing. 


\subsection{Photogrammetry of termite mounds}

The PG method to determine epigeal volume and surface area of TMs consists of three steps: (i) image acquisition, (ii) digital reconstruction of the TM via SfM algorithms, and (iii) scaling and measurement of the reconstructed TM model (Fig. S1 in the Supplement). For the image acquisition step, any vegetation and debris within $1-2 \mathrm{~m}$ of the selected TM were removed to obtain unobstructed views from all angles. The TM-soil intersection was carefully cleaned with a brush. The basal perimeter of the TM was determined by tapping or scraping the soil surface and mound, then marked with a bright-coloured marker spray (Fig. S1b). Reference objects of known dimensions, consisting of either the base of a flux chamber or two graduated rods, were placed on the ground next to the TM. For each TM, 40-50 images were acquired in RAW format using a digital mirrorless camera (Olympus E-M1, Olympus Corporation, Tokyo, Japan) with a 18-200 multi-zoom lens (Panasonic Corporation, Osaka, Japan). To ensure complete coverage and sufficient precision we followed the recommendations of Wenzel et al. (2013) for optimal image acquisition for photogrammetric image processing (see Supplement). Care was taken to ensure the reference objects were visible in all images. Image acquisition was generally completed in 10-20 min.

All computations in steps (ii) and (iii) were performed on standard laptop computers using low-cost and free software packages. For the digital reconstruction and generation of a 3-D mesh we used PhotoScan Standard 64-bit v1.2.4 (Agisoft LLC, St. Petersburg, Russia). Scaling and computation of volume and surface areas of the 3-D mesh was performed in MeshLab 64-bit v1.3.3 (Cignoni et al., 2008). After scaling with the reference objects, unnecessary parts of the mesh were deleted, with only the epigeal TM open at its base remaining ("open" mesh; Fig. S1c). A hole-filling algorithm was then applied to generate a "closed" mesh (see supporting information), and geometric measures were computed before and after closure. The surface area of the open mesh represents the epigeal TM surface area $A_{\mathrm{E}}$, the difference in surface area between open and closed mesh represents the TM's basal area $A_{\mathrm{B}}$, and the volume of the closed mesh represents the epigeal volume of the TM, $V_{\mathrm{E}}$.

For validation purposes, the PG method was applied to seven large rocks, roughly comparable in shape and size to smaller TMs $(<20 \mathrm{~L})$. The reference volumes $V_{\text {ref }}$ of the rocks were determined by water displacement using a water density of $0.998 \mathrm{~kg} \mathrm{~L}^{-1}$. The rocks were placed firmly in an upright position on flat ground, then the PG method was performed as described above. The number of photographs taken of each rock was between 37 and 42 . Surface areas $A_{\mathrm{E}}$ and $A_{\mathrm{B}}$ of the rocks were not determined; studies presenting similar photogrammetric methods found that if the volume is estimated accurately by the method, the surface area is similarly accurate (Lavy et al., 2015). The PG method was applied 4 times to one rock to estimate coefficients of variation.

\subsection{Flux measurements}

Gas exchange of $\mathrm{CH}_{4}$ was measured according to the protocol described in Jamali et al. (2011). Briefly, closed dynamic chambers built from polyvinyl chloride bins were placed over the selected TM and fixed on previously installed collars reaching $3-5 \mathrm{~cm}$ deep into the soil. The chambers were open to soil with a total volume $\left(V_{\mathrm{Ch}}\right)$ of 28,90 or $150 \mathrm{~L}$, depending on the size of the TM. During 5-10 min of chamber deployment, $\mathrm{CH}_{4}$ concentration change was measured with an optical gas analyser (Fast Greenhouse Gas Analyzer, Los Gatos Research, Mountain View, CA) connected to the chamber in a closed loop.

\subsection{Cross-sectioning estimate of mound porosities}

To estimate the internal volume fractions of a TM we developed a simple method based on cross-sectioning of excavated TMs and subsequent image analysis. The method requires two assumptions: (i) the TM is roughly symmetric around a rotational $(z)$ axis, and (ii) the macro-pores are distributed evenly in $x$ and $y$ directions (Fig. 1). Under these assumptions, the areal ratio of macro-pores vs. full mound $\theta_{\mathrm{M}, \mathrm{A}}\left(A_{\mathrm{M}} / A_{\mathrm{F}} ;\right.$ Fig. 1$)$ in a single cross section through the TM centre should approach the TM macro-porosity $\theta_{\mathrm{M}, \mathrm{V}}$.

The cross-sectioning was performed in the laboratory on $17 \mathrm{TMs}$ previously excavated for CT scanning for direct comparison of the two methods. The selected TMs were firmly embedded in a box with sand, then carefully cut with a manual wood saw from the top centre downwards (Fig. S2a). Care was taken not to break the outer walls of the TM, especially in the hypogeal part of the TM where pieces of gravel were prevalent and embedded in the walls. Damaged parts were excluded from analysis. The cross section was then painted with a bright colour using a paint roller to highlight the TM wall surface, thereby creating a distinct, uniform surface independent of the properties of the mound material (Fig. S3a). The painted cross section was photographed with the same camera system used for the PG method. The nonpainted half of the TM was broken down to sample termites, then weighted and dried at $105^{\circ} \mathrm{C}$ for $48 \mathrm{~h}$ to determine the water content.

Image analysis was performed using the Fiji software package (Schindelin et al., 2012). The original colour image was converted to binary with a colour threshold of \pm 25 hue values around the hue maximum of the paint in the HSB colour space (Fig. S3b). To close the macro-pores and generate a cross section of the "full" mound, the initial binary image was segmented and subsequently filled (Fig. S3c). The difference of the initial and filled binary image represented the area of the macro-pores in the cross section, $A_{\mathrm{M}}$; this was divided by the area of the segmented (full) TM, $A_{\mathrm{F}}$, to calculate the areal cross-sectional macro-porosity $\theta_{\mathrm{M}, \mathrm{A}}$ of the TM. 
Table 1. Calculation of TM internal parameters from physical measures of mass, volume and area fractions (see Fig. 1). The TM mass $m_{\mathrm{F}}$ refers to dry mass; water content was determined from the oven-dry weight and subtracted from field weight. Mass of termites and potential food stores were considered negligible; thus $m_{\mathrm{F}}$ is essentially identical to the mass of wall material, $m_{\mathrm{W}}$. Particle density $\rho_{\mathrm{b}}$ of the TM was assumed to be $2.65 \mathrm{~kg} \mathrm{~L}^{-1}$, typical for soil particles.

\begin{tabular}{lll}
\hline Parameter & Unit & Equations \\
\hline Bulk density & $\mathrm{kg} \mathrm{L}^{-1}$ & $\rho_{\mathrm{b}}=\frac{m_{\mathrm{F}}}{V_{\mathrm{F}}}$ \\
Wall density & $\mathrm{kg} \mathrm{L}^{-1}$ & $\rho_{\mathrm{W}}=\frac{m_{\mathrm{W}}}{V_{\mathrm{W}}} \cong \frac{m_{\mathrm{F}}}{V_{\mathrm{W}}}$ \\
Particle density & $\mathrm{kg} \mathrm{L}^{-1}$ & $\rho_{\mathrm{p}}=\frac{m_{\mathrm{F}}}{V_{\mathrm{P}}} \approx 2.65$ \\
Macro-porosity (volumetric ratio) & $\mathrm{LL}^{-1}$ & $\theta_{\mathrm{M}, \mathrm{V}}=\frac{V_{\mathrm{M}}}{V_{\mathrm{F}}}=1-\frac{\rho_{\mathrm{b}}}{\rho_{\mathrm{W}}}$ \\
Macro-porosity (areal ratio) & $\mathrm{LL}^{-1}$ & $\theta_{\mathrm{M}, \mathrm{A}}=\frac{A_{\mathrm{M}}}{A_{\mathrm{F}}} \approx \frac{V_{\mathrm{M}}}{V_{\mathrm{F}}}$ \\
Micro-porosity & $\mathrm{LL}^{-1}$ & $\theta_{\mu}=\frac{V_{\mu}}{V_{\mathrm{F}}}=1-\theta_{\mathrm{M}}-\frac{\rho_{\mathrm{b}}}{\rho_{\mathrm{p}}}$ \\
Wall porosity & $\mathrm{LL}^{-1}$ & $\theta_{\mathrm{W}}=\frac{V_{\mu}}{V_{\mathrm{W}}}=1-\frac{\rho_{\mathrm{W}}}{\rho_{\mathrm{p}}}$ \\
Total porosity & $\mathrm{LL}^{-1}$ & $\theta_{\mathrm{t}}=\frac{V_{\mathrm{M}}+V_{\mu}}{V_{\mathrm{F}}}=\theta_{\mathrm{M}}+\theta_{\mu}=1-\frac{\rho_{\mathrm{b}}}{\rho_{\mathrm{p}}}$
\end{tabular}

\subsection{Computer tomography of excavated termite mounds}

To perform a complete assessment of the internal physical characteristics of TMs we scanned 17 selected TMs with Xray computer tomography using a medical $\mathrm{CT}$ instrument (Philips Ingenuity; Koninklijke Philips N.V., North Ryde NSW, Australia; for technical details see supporting information). Images issued from the scanner (Fig. S4a) were imported into Fiji for conversion to binary (Fig. S4b) and subsequent filling of the macro-pores (Fig. S4c), similar to the cross-sectioning method. The full volume and volume fractions of the walls and macro-pores were computed with MATLAB and its Image Processing and Computer Vision Toolbox (Release 2015b, The Mathworks Inc., Natick MA, United States) by populating a 3-D matrix from the initial and filled binary images, counting the number of voxels and scaling with the respective voxel dimensions from the CT scan. To directly compare the cross-sectioning method with CT we also computed areal ratios of $A_{\mathrm{M}} / A_{\mathrm{F}}$ and thus estimated $\theta_{\mathrm{M}, \mathrm{A}}$ from CT slices in the $x z$ and $y z$ directions of the populated matrix. Only the $10 \%$ of slices with the largest area were used to represent cross sections close to the centre and tip of the TMs.

\subsection{Calculations and statistical analyses}

Internal TM parameters and their calculation from mass, volume and area fractions are given in Table 1. In addition, we determined surface-to-volume ratios $A_{\mathrm{E}} / V_{\mathrm{E}}$ and the fractal dimension $D$ to quantify morphological differences between termite species. Surface-to-volume ratios were calculated directly from PG estimates. Calculation of the 3-D fractal dimension from Wavefront .obj files of TM PG models $\left(D_{\mathrm{PG}}\right)$ was based on the MinkowskiBouligand method at the 3-D level (Backes et al., 2010), using the freely available Bouligand-Minkowski 3D-Toolbox (https://www.facom.ufu.br/ backes/mink3d.html, last access: 12 June 2018). Further details on the method and toolbox can be found in Reichert et al. (2017).

The $\mathrm{CH}_{4}$ flux $F_{\mathrm{CH}_{4}}\left(\mu \mathrm{mol} \mathrm{m}{ }^{-2} \mathrm{~h}^{-1}\right)$ from TMs was calculated from the change in $\mathrm{CH}_{4}$ concentration $C_{\mathrm{CH}_{4}}$ over time $t$ in the chamber headspace, after correcting $\mathrm{C}_{\mathrm{CH}_{4}}$ for ambient temperature and pressure:

$F_{\mathrm{CH}_{4}}=\left(\mathrm{d} C_{\mathrm{CH}_{4}} / \mathrm{d} t\right) \cdot\left(\left(V_{\mathrm{Ch}}-V_{\mathrm{E}}\right) / A_{\mathrm{B}}\right)$.

Method differences were assessed via ordinary least-square regression with zero intercept (assuming homoscedasticity and negligible errors in the reference data). Confidence intervals were calculated from $t$ statistics. Significant differences $(\alpha=0.05)$ between termite species' structural parameters were tested with One-Way ANOVA, and correlations between epigeal measures with ordinary least-square regression. Statistical calculations and analyses were performed using R Statistical Software (R Development Core Team, 2017).

\section{Results}

\subsection{Epigeal volume and surface area of termite mounds}

Verification of the PG method to determine $V_{\mathrm{TM}}, A_{\mathrm{TM}}$ and $A_{\mathrm{B}}$ was performed on seven large rocks with known $V_{\text {Ref }}$ (determined by water displacement; Fig. 2). For all rocks and TMs, no failures were experienced during alignment and matching; the procedure always resulted in highquality meshes without structural deficiencies. The estimated volumes $V_{\mathrm{PG}}$ were significantly correlated with $V_{\mathrm{Ref}}$ $(P<0.001)$ across all rock sizes. On average, the $P G$ method slightly underestimated rock volumes by $1.3 \pm 0.65 \%$. The largest relative error encountered was $-3.5 \%$ for the smallest measured rock. Repeated application of the PG method 


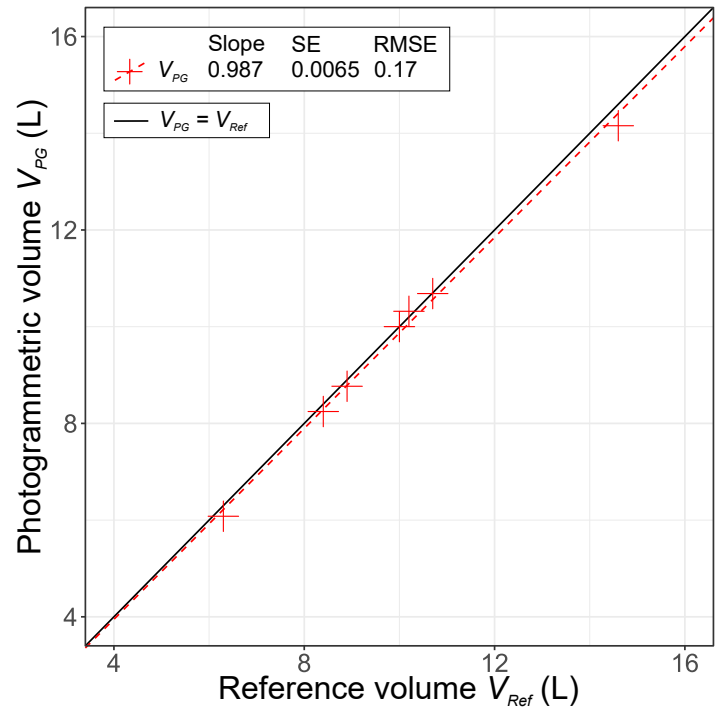

Figure 2. Validation of the photogrammetry method (PG) by estimating the volumes of seven irregularly shaped rocks with similar volumes to small termite mounds. The dashed line indicates the linear regression between $V_{\mathrm{PG}}$ and $V_{\mathrm{Ref}}$, with slope, standard error (SE) and root mean square error (RMSE); the black solid line denotes perfect correlation.

for one rock resulted in a coefficient of variation of $0.6 \%$ for $V_{\mathrm{PG}}, 0.8 \%$ for $A_{\mathrm{PG}}$ and $7.8 \%$ for $A_{\mathrm{B}}$.

The epigeal volume $V_{\mathrm{E}}$ of the 29 investigated TMs spanned across 2 orders of magnitude (Fig. 3 and Table S1). Mounds of $M$. nervosus were the smallest (4.6-18 L), followed by M. sunteri (5.2-190L) and T. pastinator (6.6$270 \mathrm{~L})$. Epigeal surface area $A_{\mathrm{E}}$ of the TMs was closely related to volume and ranged between 0.17 and $2.3 \mathrm{~m}^{2}$, basal area $A_{\mathrm{B}}$ between 0.028 and $1.1 \mathrm{~m}^{2}$ (Table S1). Correlations with $V_{\mathrm{E}}$ were significant for both parameters, with insignificant differences between species. Basal areas calculated from the manually measured circumference at the TM-soil intersection (via ideal circle with radius $r_{\mathrm{B}}$; Table $\mathrm{S} 1$ ) were on average underestimated by 7 to $30 \%$ when compared to the PG method, and up to a factor of 5 for some TMs (e.g. Ms2) of the soil-interface feeder $M$. sunteri that featured large and irregularly shaped $A_{\mathrm{B}}$. Similarly, large differences were observed when comparing $V_{\mathrm{E}}$ from $\mathrm{PG}$ with volumes of approximated geometric shapes (Fig. 3). The cylinder approximation consistently overestimated $V_{\mathrm{E}}$ by a factor of 2 to 4 (Fig. 3) whereas $V_{\mathrm{E}}$ approximated by cones and hemispheroids was on average underestimated by only 4-7\% relative to PG estimates (although some individual TMs were under- or overestimated by factors of 2 to 3 ). Relative errors were high irrespective of the size of the TMs.

To compare potential inter-species variation in TM morphology, we computed area-to-volume ratios $A_{\mathrm{E}} / V_{\mathrm{E}}$ and $D_{\text {PG }}$ from PG models (Table 2). Area-to-volume ratios were highest for M. nervosus, slightly smaller for M. sunteri and

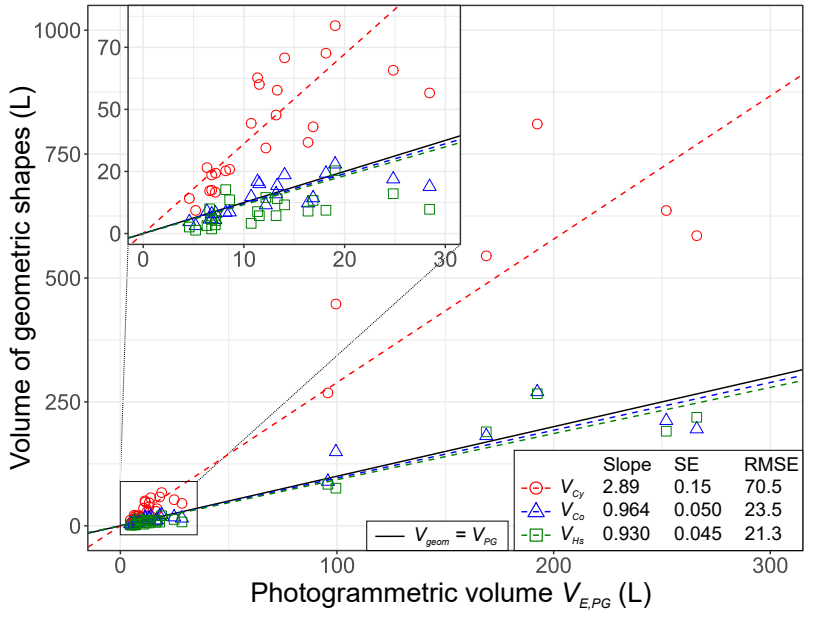

Figure 3. Comparison of TM epigeal volumes $V_{\mathrm{E}}$ measured by photogrammetry (PG) and approximated by three geometric shapes, a cylinder (in red), a cone (in blue) and a hemi-spheroid (in green; Fig. 1). The volumes of the geometric shapes are based on the same basal radius $r_{\mathrm{B}}$, estimated by measuring the basal circumference of the TM. By comparing the regression slopes and considering PG as the reference method, volumes were overestimated by $190 \pm 15 \%$ using the cylinder, and underestimated by $3.6 \pm 5$ and $7.0 \pm 4.5 \%$ using the cone and hemi-spheroid, respectively.

significantly smaller for T. pastinator. This relationship held true even when considering only small and medium-sized TMs with $V_{\mathrm{E}}<30 \mathrm{~L}$. In contrast, no significant differences were found when comparing $D_{\mathrm{PG}}$ between species (Table 2); computed values were around 1.9 for all species.

\subsection{Internal termite-mound porosity and structure}

Complete characterisation of porosities and internal structure was achieved for 17 TMs using CT scanning (Fig. 4 and Table 2). Full volume $V_{\mathrm{F}}$ of the scanned TMs ranged from 6.7 to $34 \mathrm{~L}$, of which $70-75 \%$ was epigeal. Size and distribution of chambers was clearly different between the three species (Fig. 4). Mounds of T. pastinator featured thinner walls with a network of longer and larger chambers compared to the other species, and a thick outer wall with little or no chambers close to the surface. This pattern was reflected in the porosities of the TMs (Table 2). Mean $\theta_{\mathrm{M}, \mathrm{V}}$ calculated as volumetric ratio was $0.24 \pm 0.04$ and $19 \pm 0.05$ for M. nervosus and $M$. sunteri, respectively, significantly lower than T. pastinator with $0.36 \pm 0.04$. An inverse pattern was observed for $\theta_{\mu}$ and $\theta_{\mathrm{W}}$ (corresponding to TM wall density $\rho_{\mathrm{W}}$ ), with walls of $T$. pastinator mounds being the least porous (Table 2). The mean total porosity $\theta_{\mathrm{t}}$ (corresponding to TM bulk density $\rho_{\mathrm{B}}$ ) was nearly identical for the three species (Table 2).

The cross-sectioning method, a simple field-based approach to estimate macro-porosity $\theta_{\mathrm{M}, \mathrm{A}}$ from areal ratios of single cross sections, was compared against $\theta_{\mathrm{M}, \mathrm{A}}$ and $\theta_{\mathrm{M}, \mathrm{V}}$ 

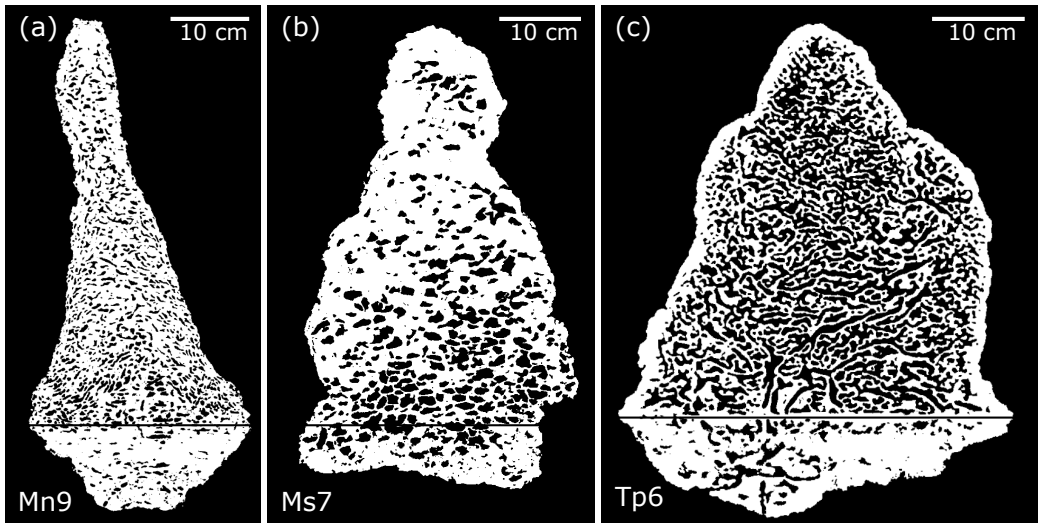

Figure 4. Binary image of a single CT slice in $x z$ direction for each investigated species: (a) Microcerotermes nervosus, (b) Macrognathotermes sunteri, (c) Tumulitermes pastinator. The thin black line approximately indicates the soil surface.

Table 2. Mean physical and morphological parameters of TMs from three termite species. Errors represent $95 \%$ confidence intervals; significance levels of the one-way ANOVA to test differences between species are indicated with *.

\begin{tabular}{|c|c|c|c|}
\hline & Microcerotermes nervosus & Macrognathotermes sunteri & Tumulitermes pastinator \\
\hline PG method & $n=10$ & $n=10$ & $n=9$ \\
\hline Epigeal surface-to-volume ratio $A_{\mathrm{E}} / V_{\mathrm{E}}\left(\mathrm{cm}^{2} \mathrm{~cm}^{-3}\right)^{* *}$ & $0.29 \pm 0.030$ & $0.24 \pm 0.059$ & $0.18 \pm 0.053$ \\
\hline Fractal dimension $D_{\mathrm{PG}}$ & $1.88 \pm 0.046$ & $1.91 \pm 0.045$ & $1.93 \pm 0.058$ \\
\hline CT scans & $n=6$ & $n=5$ & $n=6$ \\
\hline Macro-porosity $\theta_{\mathrm{M}, \mathrm{V}^{* * *}}$ & $0.24 \pm 0.043$ & $0.19 \pm 0.046$ & $0.36 \pm 0.037$ \\
\hline Micro-porosity $\theta_{\mu}{ }^{* * *}$ & $0.35 \pm 0.058$ & $0.39 \pm 0.074$ & $0.23 \pm 0.019$ \\
\hline Total porosity $\theta_{\mathrm{t}}$ & $0.59 \pm 0.051$ & $0.58 \pm 0.044$ & $0.58 \pm 0.022$ \\
\hline Bulk density $\rho_{\mathrm{B}}\left(\mathrm{kg} \mathrm{L}^{-1}\right)$ & $1.10 \pm 0.14$ & $1.10 \pm 0.12$ & $1.10 \pm 0.060$ \\
\hline Wall density $\rho_{\mathrm{W}}{ }^{* *}\left(\mathrm{~kg} \mathrm{~L}^{-1}\right)$ & $1.43 \pm 0.18$ & $1.36 \pm 0.18$ & $1.71 \pm 0.040$ \\
\hline Wall porosity $\theta_{\mathrm{W}}{ }^{* *}$ & $0.46 \pm 0.067$ & $0.49 \pm 0.067$ & $0.35 \pm 0.015$ \\
\hline Epigeal ratio $V_{\mathrm{E}} / V_{\mathrm{F}}$ & $0.74 \pm 0.092$ & $0.73 \pm 0.096$ & $0.70 \pm 0.094$ \\
\hline Cross-sectioning & $n=6$ & $n=5$ & $n=6$ \\
\hline Macro-porosity $\theta_{\mathrm{M}, \mathrm{A}^{* * *}}$ & $0.25 \pm 0.039$ & $0.20 \pm 0.050$ & $0.49 \pm 0.071$ \\
\hline
\end{tabular}

Significance levels: ${ }^{* * *} P<0.001 ;{ }^{* *} 0.001<P<0.01$; $^{*} 0.01<\mathrm{P}<0.05$.

from CT scanning (Fig. 5 and Table 2). For M. nervosus and $M$. sunteri mounds, $\theta_{\mathrm{M}, \mathrm{A}}$ from cross-sectioning were 0.25 and 0.20 respectively, nearly identical to $\theta_{\mathrm{M}, \mathrm{V}}$ from CT scans and with a mean error of $+3 \%$. Similarly, for $M$. nervosus and $M$. sunteri mounds the $\theta_{\mathrm{M}, \mathrm{A}}$ from the largest $10 \%$ of CT slices encompassed values of $\theta_{\mathrm{M}, \mathrm{A}}$ estimated from crosssectioning (Fig. 5). The error in $\theta_{\mathrm{M}, \mathrm{A}}$ from CT slices compared to $\theta_{\mathrm{M}, \mathrm{V}}$ from full CT scans, i.e. the bias of calculating $\theta_{\mathbf{M}}$ from areal ratios of slices instead of volumetric ratios, was around $\pm 3 \%$ for $M$. nervosus and M. sunteri. In contrast, for T. pastinator mounds $\theta_{\mathrm{M}, \mathrm{A}}$ from cross-sectioning was $0.49 \pm 0.07$, substantially higher than $\theta_{\mathrm{M}, \mathrm{V}}(0.36 \pm 0.04)$; the mean error was $+38 \%$ (Fig. 5 and Table 2). When comparing $\theta_{\mathrm{M}, \mathrm{A}}$ from CT slices with $\theta_{\mathrm{M}, \mathrm{V}}$ from full CT scans there was a mean bias of $+17 \%$ for T. pastinator mounds. Despite these differences between species when estimating porosity, the fractal dimension from cross sections, $D_{\mathrm{Xsec}}$, was similar between species and compared to $D_{\mathrm{CT}}$ (Table 2).

\subsection{Termite-mound methane flux}

Fluxes of $\mathrm{CH}_{4}$ across the TM-atmosphere interface were calculated according to Eq. (1) using volume and basal area measured with $\mathrm{PG}\left(F_{\mathrm{PG}}\right)$, or approximated by geometric shapes $\left(F_{\text {geom }}\right)$ that shared the same height $h$ and basal radius $r_{\mathrm{B}}$. All but one of the TMs were a source of $\mathrm{CH}_{4}$ to the atmosphere, with net fluxes $F_{\mathrm{PG}}$ ranging from 42 to $960 \mu \mathrm{mol} \mathrm{CH}_{4} \mathrm{~m}^{-2} \mathrm{~h}^{-1}$. Assuming $F_{\mathrm{PG}}$ was the reference, mean errors of $F_{\text {geom }}$ were on average $14-48 \%$, depending on the geometric shape (Fig. 6). Compared against $F_{\mathrm{PG}}$, the cylinder approximation $\left(F_{\mathrm{Cy}}\right)$ performed better than the cone $\left(F_{\mathrm{Co}}\right)$ and hemi-spheroid $\left(F_{\mathrm{Hs}}\right)$, despite grossly overestimating $V_{\mathrm{E}}$. Mounds of $M$. sunteri showed the largest differences between $F_{\mathrm{PG}}$ and $F_{\text {geom }}$, up to a factor of 5 for mound Ms2. When excluding mounds with high leverage from the regression model (Ms1 and Ms2, Fig. 6), mean errors of $F_{\mathrm{Co}}$ and $F_{\mathrm{Hs}}$ improved to 11 and $12 \%$, with 49 and 


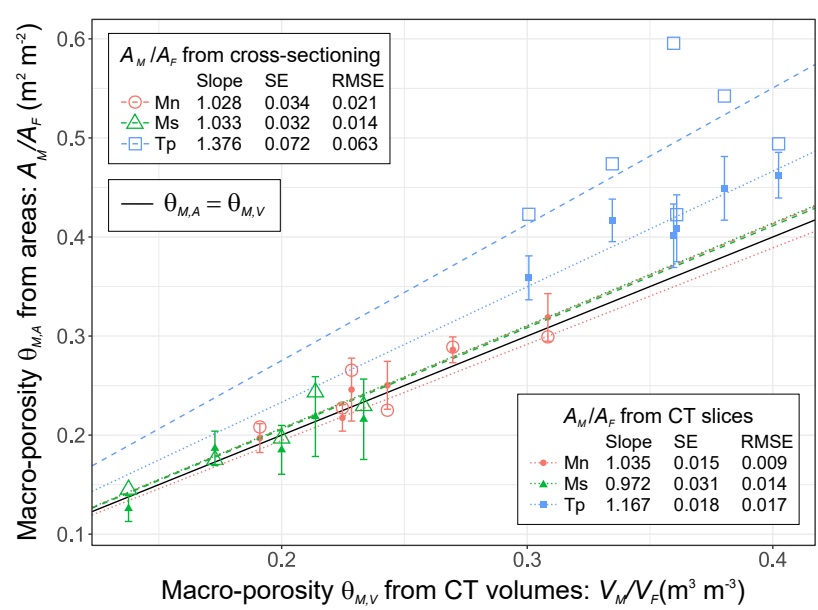

Figure 5. Comparison of areal estimates of TM macro-porosity $\theta_{\mathrm{M}, \mathrm{A}}$ against volumetric estimates of TM macro-porosity $\theta_{\mathrm{M}, \mathrm{V}}$ for each CT-scanned TM. Volumetric estimates were calculated from full CT scans; areal estimates were obtained via manual crosssectioning of TMs (open symbols), and from individual CT slices in $x z$ and $y z$ directions (closed symbols). The latter represent the mean $\theta_{\mathrm{M}, \mathrm{A}} \pm 95 \%$ confidence intervals of the $10 \%$ of slices with the largest area, thus covering the tip (and likely the centre) of the TM.

$52 \mu \mathrm{mol} \mathrm{CH} \mathrm{m}^{-2} \mathrm{~h}^{-1} \mathrm{RMSE}$, respectively; $F_{\text {Cyl }}$ remained at $14 \%$ and $200 \mu \mathrm{mol} \mathrm{CH}_{4} \mathrm{~m}^{-2} \mathrm{~h}^{-1}$ RMSE.

\section{Discussion}

\subsection{Photogrammetry of termite mounds}

Applying the PG approach to TMs of three common termite species allowed us to accurately determine $V_{\mathrm{E}}, A_{\mathrm{E}}$ and $A_{\mathrm{B}}$ with a single method that took on average $15 \mathrm{~min}$ of field work per mound. This is close to the time required for determining height and circumference of larger and more complex Macrotermes TMs (Darlington and Dransfield, 1987). While being simple and rapid to apply in the field, the PG approach is clearly superior in accuracy to any traditional approach for estimating $V_{\mathrm{E}}$ based on simple geometric shapes (Fig. 3). Such an accurate $V_{\mathrm{E}}$ can then be the basis of reasonable termite population estimates, if subsamples of TMs are representative for the whole in termite numbers and composition, and their volume is determined equally accurately (Jones et al., 2005). However, the largest uncertainties are likely not derived from errors in estimating $V_{\mathrm{E}}$, but rather in the immobilisation and counting of within-mound termite population (Darlington, 1984; Jones et al., 2005).

The PG method also allows rapid and accurate determination of surface-to-volume ratios of TMs with different and complex morphologies. This enables the collection of large data sets on TM morphology to test hypotheses relating to the role of mound structure in determining gas exchange

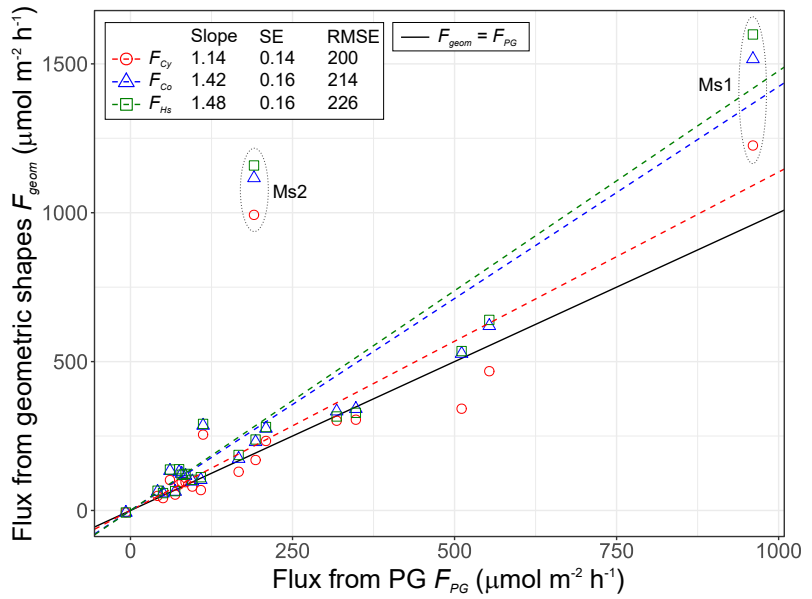

Figure 6. Comparison of $\mathrm{CH}_{4}$ flux calculated according to Eq. (1) with TM epigeal volumes $V_{\mathrm{TM}}$ and basal areas $A_{\mathrm{B}}$ from photogrammetry $\left(F_{\mathrm{PG}}\right)$, and with TM volumes approximated by three geometric shapes: a cylinder $\left(F_{\mathrm{Cy}}\right)$, a cone $\left(F_{\mathrm{Co}}\right)$ and a hemispheroid $\left(F_{\mathrm{Hs}}\right)$. Considering PG as the reference method, fluxes were overestimated by $14 \pm 14 \%$ for the cylinder, $42 \pm 16 \%$ for the cone and $48 \pm 16 \%$ for the hemi-spheroid.

and thermal homeostasis. To date such analyses have been compromised by small sample sizes (Korb and Linsenmair, 1999). Our data demonstrate this by revealing significant differences between species, with $M$. nervosus and M. sunteri having a larger surface-to-volume ratio than $T$. pastinator, despite having a significantly lower wall porosity (Table 2 ). Interestingly, we could not detect inter-species differences in the fractal dimension $D_{\mathrm{PG}}$ of the TM surface models (Table 2), even though this parameter was more sensitive than surface-to-volume ratios in describing morphological differences between corals (Reichert et al., 2017). Yet, surface-tovolume ratios have a direct physiological meaning and may integrate effects of both external and internal structural parameters of TMs, while the fractal dimension is a measure for the complexity of a shape and thus only reflects external factors. However, it may also be that the PG method does not resolve the small-scale surface morphologies as well as the industrial-grade high-resolution 3-D scanner used by Reichert et al. (2017).

The reconstruction process of the PG method and its accuracy and precision depend on several technical factors, including camera equipment and software, as has been discussed elsewhere (Koutsoudis et al., 2013, 2014; De Reu et al., 2013; Wenzel et al., 2013). In our case, natural factors and environmental conditions may be more important for a successful and accurate digital reconstruction. Even though we encountered no failures during reconstruction, Bauwens et al. (2017) reported a failure rate of $21 \%$ for the PG reconstruction process of buttressed trees, which was attributed to vegetation obscuring the trees to be photographed. Application of the PG method to TMs in open woodlands was not 
affected by vegetation which can be readily removed from the mound surroundings without significant impact. In dense tropical forests the PG method may be limited by the need to remove of trees or shrubs adjacent to the target mound. Marking the TM-soil intersection and cutting the 3-D model is another potential source of error evident from the larger $\mathrm{CV}$ of $A_{\mathrm{B}}$ compared to $V_{\mathrm{E}}$ and $A_{\mathrm{E}}$. To some extent, and specifically for soil- and litter-feeding termites, this is unavoidable, as the soil-mound boundaries are inherently fuzzy. We tried to minimise variability by careful probing and marking of the soilTM boundary, and by letting the same person do all manual editing on the 3-D mesh (Fig. S1c). In future attempts, the latter process may be automated using feature detection available in Photoscan Professional, but this software comes with a higher price tag.

\subsection{Internal termite-mound porosities}

The use of CT scanning as a reference method allowed us to accurately calculate the TMs' full, wall and chamber volume, and thus macro-and micro-porosity, as well as the epigeal ratio. Most mounds had $65-75 \%$ of their volume above ground, with little variation between species (Table 2). This is consistent with qualitative descriptions of M. nervosus and T. pastinator mounds (Abensperg-Traun and Perry, 1998; Bristow and Holt, 1987), and close to the general assumption of $75 \%$ epigeal mass stated by Josens and Soki (2010). These authors also mentioned species-specific TM bulk densities ("specific mass") of $0.95 \mathrm{~kg} \mathrm{~L}^{-1}$ for carton-based nests, and $1.2 \mathrm{~kg} \mathrm{~L}^{-1}$ for soil-based mounds, thus encompassing our values of $1.1 \mathrm{~kg} \mathrm{~L}^{-1}$. Holt et al. (1980) reported bulkand wall-density data for some northern Australian termite species and estimated a similar value $(0.40)$ for the macroporosity of $T$. pastinator (without reporting wall density).

Despite nearly identical bulk density and total porosity, our investigated species showed clearly different species-specific pore-size distributions (Table 2): TMs of M. nervosus and $M$. sunteri appeared to have the largest fraction of internal gas volume in the walls $\left(\theta_{\mathbf{M}}<\theta_{\mu}\right)$, while for $T$. pastinator the bulk of the gas was in the chambers $\left(\theta_{\mathbf{M}}>\theta_{\mu}\right)$. Another widespread north Australian termite species, Amitermes vitiosus, showed a similar TM wall density than T. pastinator $\left(1.7 \mathrm{~kg} \mathrm{~L}^{-1}\right)$, yet a significantly higher bulk density of 1.41 to $1.48 \mathrm{~kg} \mathrm{~L}^{-1}$ (Holt et al., 1980). This translates to a much lower macro-porosity (0.13) compared to the species investigated here, but a micro-porosity (0.32) similar to $M$. nervosus and $M$. sunteri. Such a pore-size distribution suggest that gas exchange may be driven by passive diffusion in M. nervosus, $M$. sunteri and A. vitiosus TMs, which is likely to limit the colony's respiration and thus total size (Josens and Soki, 2010), but may provide additional insulation in the high-temperature habitats of the tropical savanna (Holt et al., 1980). In contrast, pore-size distribution and surface-tovolume ratios in $T$. pastinator TMs hints towards a convective internal mixing mechanism to facilitate diffusion across the dense outer walls (Bristow and Holt, 1987; King et al., 2015).

The simple cross-sectioning method presented here worked well for $M$. nervosus and $M$. sunteri and allowed rapid, accurate estimation of TM porosities when combined with PG and bulk density estimates. Yet, both species featured evenly distributed macro-pores and relatively thick, porous walls. In contrast, T. pastinator featured thick dense outer walls and thin inner walls, and thus an asymmetric radial distribution of macro-pores. Therefore, the outer walls are under-represented when extrapolating from a 2-D slice to a 3-D structure due to the cubic increase in volume with radius. This likely explains the $17 \%$ bias when comparing $\theta_{\mathrm{M}, \mathrm{A}}$ from individual CT slices to $\theta_{\mathrm{M}, \mathrm{V}}$ from full $\mathrm{CT}$ scans. In addition, the manual sawing was sometimes damaging the thin, brittle internal walls found in T. pastinator, thus resulting in additional positive errors in $\theta_{\mathrm{M}, \mathrm{A}}$ compared to $\theta_{\mathrm{M}, \mathrm{V}}$.

Consequently, the cross-sectioning method will work best on epigeal TMs with thick, firm walls and an even distribution of chambers. For TMs with an uneven distribution of chambers or brittle walls, an alternative approach for estimating macro- and micro-porosity can be entirely based on PG by determining TM wall density with the "clodometer" method (a PG adaptation of the soil-clod method; Stewart et al., 2012), and the PG method described here for epigeal TM bulk density. Macro- and micro-porosity can then be calculated according to Eqs. (5) and (7).

\subsection{Improved biogeochemical flux estimation}

Using PG measures of TMs substantially improved the accuracy of $\mathrm{CH}_{4}$ flux measurements compared to conventional approaches by $15-50 \%$ on average, and up to a factor of 4 for individual TMs (Fig. 6). Interestingly, the cylinder approximation performed better than cone or hemi-spheroid, even though $V_{\mathrm{E}}$ was grossly overestimated; this illustrates that (i) errors in $V_{\mathrm{E}}$ and $A_{\mathrm{B}}$ compensate each other to some extent, as the two measures are linked, and (ii) errors in $V_{\mathrm{E}}$ are masked if the flux chamber volume $V_{\mathrm{Ch}}$ is much larger than $V_{\mathrm{E}}$. In general, errors in fluxes due to errors in basic geometric measures were significant and can largely be avoided using the PG method. Compared to destructive water displacement measurements, the PG method preserves the integrity of the TM and allows repeated flux measurements to capture seasonal or diurnal trends (Jamali et al., 2011). In combination with species-specific bulk density and porosity information, it is even possible to compare biogeochemical rates based on the mass of the TM without destroying the mound. This is relevant for microbial processes that occur in the wall material, such as microbial respiration or $\mathrm{CH}_{4}$ oxidation (Ho et al., 2013; Holt, 1998; Sugimoto et al., 1998). Furthermore, fluxes of termite respiratory gases $\left(\mathrm{CO}_{2}\right.$ and $\mathrm{O}_{2}$ ) can be accurately related to the TM surface area $A_{\mathrm{E}}$ to calculate specific "respiration coefficients" (i.e. the rate of gas exchange per surface area) for comparison of the respi- 
ratory efficiency of different TM architectures (Josens and Soki, 2010). In an open savanna landscape, it may also be possible to estimate TM abundance and size with the PG method using drones as an inexpensive alternative to lidar systems (Davies et al., 2014; Verhoeven, 2011). Long-term aerial monitoring of TMs may thus inform not only on a spatial but also on a temporal scale, e.g. on TM growth and decay rates, as well as temporal shifts in abundance. Furthermore, combining such information with biogeochemical rates has the potential to greatly improve the accuracy of landscape-, continental- or even global-scale emission estimates of termite-produced greenhouse gases (Livesley et al., 2011; Saunois et al., 2016).

\section{Conclusions}

The external and internal structures of TMs have been inherently difficult to quantify due to a lack of appropriate methods. Yet, such measures are the basis of most assessments of termite-related biogeochemical processes. The presented PG method is the first to provide rapid, convenient estimates of epigeal volume and surface areas in one application, without destroying the TM. Its application on different termite species revealed large errors in TM volumes approximated by simple shapes. We therefore recommend the PG method for any future investigations where TM volumes and surface areas are required, particularly when measuring TM greenhouse-gas fluxes. We proposed macro- and microporosities as a meaningful yet simple quantitative measure of TM structure. The image-based cross-sectioning method to estimate macro-porosity works well for TMs with uniform chamber distribution and thick walls; for other mound types, the outlined approach based entirely on PG is recommended. Pore-size distributions and surface-to-volume ratios appear to be highly species-specific and provide simple means for future studies to quantitatively test hypotheses on termites' various strategies to maintain homeostasis and efficient gas exchange.

Data availability. All data, imagery, 3-D models and scripts are available at https://doi.org/10.5061/dryad.587bb57.

\section{The Supplement related to this article is available online at https://doi.org/10.5194/bg-15-3731-2018-supplement.}

Author contributions. PN and SA conceived the ideas and designed the methodology. PN, DdS and EC collected the data. PN and EC analysed the data. PN, SA and LH led the writing of the paper. All authors contributed critically to the drafts and gave final approval for publication.
Competing interests. The authors declare that they have no conflict of interest.

Acknowledgements. The study was supported by funding from the Australian Research Council (ARC) grants DP120101735 and LP100100073. Philipp Nauer is grateful to the Swiss National Science Foundation (SNF) for his Early Postdoc.Mobility fellowship P2EZP3_155596. The authors sincerely thank Matthew Northwood for technical assistance, Linda Luck for help with field work, Theodore Evans for help with termite identification, and André Backes for assistance with 3-D fractal dimension calculations.

Edited by: Nobuhito Ohte

Reviewed by: four anonymous referees

\section{References}

Abensperg-Traun, M. and Perry, D. H.: Distribution and characteristics of mound-building termites (Isoptera), J. R. Soc. West. Aust., 81, 191-200, 1998.

Backes, A. R., Eler, D. M., Minghim, R., and Bruno, O. M.: Characterizing 3D Shapes Using Fractal Dimension, in: Progress in Pattern Recognition, Image Analysis, Computer Vision, and Applications, edited by: Bloch, I. and Cesar, R. M., 14-21, Springer Berlin Heidelberg, Berlin Heidelberg, 2010.

Bauwens, S., Fayolle, A., Gourlet-Fleury, S., Ndjele, L. M., Mengal, C., and Lejeune, P.: Terrestrial photogrammetry: a non-destructive method for modelling irregularly shaped tropical tree trunks, Methods Ecol. Evol., 8, 460-471, https://doi.org/10.1111/2041-210X.12670, 2017.

Bristow, K. L. and Holt, J. A.: Can termites create local energy sinks to regulate mound temperature?, J. Therm. Biol., 12, 1921, https://doi.org/10.1016/0306-4565(87)90018-0, 1987.

Brümmer, C., Papen, H., Wassmann, R., and Brüggemann, N.: Fluxes of $\mathrm{CH}_{4}$ and $\mathrm{CO}_{2}$ from soil and termite mounds in south Sudanian savanna of Burkina Faso (West Africa), Global Biogeochem. Cy., 23, 1-13, https://doi.org/10.1029/2008GB003237, 2009.

Cignoni, P., Callieri, M., Corsini, M., Dellepiane, M., Ganovelli, F., and Ranzuglia, G.: MeshLab: an Open-Source Mesh Processing Tool, in: Sixth Eurographics Italian Chapter Conference, 129136, Eurographics Association, Geneva, Switzerland, 2008.

Darlington, J. P. E. C.: A method for sampling the populations of large termite nests, Ann. Appl. Biol., 104, 427-436, https://doi.org/10.1111/j.1744-7348.1984.tb03024.x, 1984.

Darlington, J. P. E. C.: Population nests of the termite Macrotermes subhyalinus in Kenya, Insect. Soc., 37, 158-168, 1990.

Darlington, J. P. E. C. and Dransfield, R. D.: Size relationships in nest populations and mound parameters in the termite Macrotermes michaelseni in Kenya, Insect. Soc., 34, 165-180, https://doi.org/10.1007/BF02224082, 1987.

Davies, A. B., Levick, S. R., Asner, G. P., Robertson, M. P., van Rensburg, B. J., and Parr, C. L.: Spatial variability and abiotic determinants of termite mounds throughout a savanna catchment, Ecography., 37, 852-862, https://doi.org/10.1111/ecog.00532, 2014. 
De Reu, J., Plets, G., Verhoeven, G., De Smedt, P., Bats, M., Cherretté, B., De Maeyer, W., Deconynck, J., Herremans, D., Laloo, P., Van Meirvenne, M., and De Clercq, W.: Towards a three-dimensional cost-effective registration of the archaeological heritage, J. Archaeol. Sci., 40, 1108-1121, https://doi.org/10.1016/j.jas.2012.08.040, 2013.

Eom, Y. H., Perna, A., Fortunato, S., Darrouzet, E., Theraulaz, G., and Jost, C.: Network-based model of the growth of termite nests, Phys. Rev. E, 92, 1-9, https://doi.org/10.1103/PhysRevE.92.062810, 2015.

Ho, A., Erens, H., Mujinya, B. B., Boeckx, P., Baert, G., Schneider, B., Frenzel, P., Boon, N., and Van Ranst, E.: Termites facilitate methane oxidation and shape the methanotrophic community, Appl. Environ. Microbiol., 79, 7234-7240, https://doi.org/10.1128/AEM.02785-13, 2013.

Holt, J.: Microbial activity in the mounds of some Australian termites, Appl. Soil Ecol., 9, 183-187, https://doi.org/10.1016/S0929-1393(98)00073-0, 1998.

Holt, J. A., Coventry, R. J., and Sinclair, D. F.: Some aspects of the biology and pedological significance of moundbuilding termites in a red and yellow earth landscape near charters towers, north queensland, Aust. J. Soil Res., 18, 97-109, https://doi.org/10.1071/SR9800097, 1980.

Jamali, H., Livesley, S. J., Dawes, T. Z., Cook, G. D., Hutley, L. B., and Arndt, S. K.: Diurnal and seasonal variations in $\mathrm{CH}_{4}$ flux from termite mounds in tropical savannas of the Northern Territory, Australia, Agr. Forest Meteorol., 151, 1471-1479, https://doi.org/10.1016/j.agrformet.2010.06.009, 2011.

Jones, D. T., Verkerk, R. H. J., and Eggleton, P.: Methods for sampling termites, in: Insect sampling in forest ecosystems, edited by: Leather, S. R., 221-253, Blackwell Science Ltd., Malden, MA, 2005.

Josens, G. and Soki, K.: Relation between termite numbers and the size of their mounds, Insect. Soc., 57, 303-316, https://doi.org/10.1007/s00040-010-0085-2, 2010.

Kandasami, R. K., Murthy, T. G., and Borges, R. M.: Effect of biocementation on the strength and stability of termite mounds, Environ. Geotech., 3, 99-113, https://doi.org/10.1680/jenge.15.00036, 2016.

Khalil, M. A. K., Rasmussen, R. A., French, J. R., and Holt, J.: The influence of Termites on Atmospheric Trace Gases: $\mathrm{CH}_{4}, \mathrm{CO}_{2}$, $\mathrm{N}_{2} \mathrm{O}$, CO, and Light Hydrocarbons, J. Geophys. Res., 95, 36193634, 1990 .

King, H., Ocko, S., and Mahadevan, L.: Termite mounds harness diurnal temperature oscillations for ventilation, P. Natl. Acad. Sci. USA, 112, 11589-11593, https://doi.org/10.1073/pnas.1423242112, 2015.

Kirschke, S., Bousquet, P., Ciais, P., Saunois, M., Canadell, J. G., Dlugokencky, E. J., Bergamaschi, P., Bergmann, D., Blake, D. R., Bruhwiler, L., Cameron-Smith, P., Castaldi, S., Chevallier, F., Feng, L., Fraser, A., Heimann, M., Hodson, E. L., Houweling, S., Josse, B., Fraser, P. J., Krummel, P. B., Lamarque, J.F., Langenfelds, R. L., Le Quéré, C., Naik, V., O’Doherty, S., Palmer, P. I., Pison, I., Plummer, D., Poulter, B., Prinn, R. G., Rigby, M., Ringeval, B., Santini, M., Schmidt, M., Shindell, D. T., Simpson, I. J., Spahni, R., Steele, L. P., Strode, S. A., Sudo, K., Szopa, S., van der Werf, G. R., Voulgarakis, A., van Weele, M., Weiss, R. F., Williams, J. E., and Zeng, G.: Three decades of global methane sources and sinks, Nat. Geosci., 6, 813-823, https://doi.org/10.1038/ngeo1955, 2013.

Korb, J.: Termite mound architecture, from function to construction, in: Biology of Termites: a Modern Synthesis, edited by: Bignell, D. E., Roisin, Y., and Lo, N., 349-373, Springer, the Netherlands, 2011.

Korb, J. and Linsenmair, K. E.: The architecture of termite mounds: a result of a trade-off between thermoregulation and gas exchange?, Behav. Ecol., 10, 312-316, https://doi.org/10.1093/beheco/10.3.312, 1999.

Koutsoudis, A., Vidmar, B., and Arnaoutoglou, F.: Performance evaluation of a multi-image $3 \mathrm{D}$ reconstruction software on a low-feature artefact, J. Archaeol. Sci., 40, 4450-4456, https://doi.org/10.1016/j.jas.2013.07.007, 2013.

Koutsoudis, A., Vidmar, B., Ioannakis, G., Arnaoutoglou, F., Pavlidis, G., and Chamzas, C.: Multi-image 3D reconstruction data evaluation, J. Cult. Herit., 15, 73-79, https://doi.org/10.1016/j.culher.2012.12.003, 2014.

Lavy, A., Eyal, G., Neal, B., Keren, R., Loya, Y., and Ilan, M.: A quick, easy and non-intrusive method for underwater volume and surface area evaluation of benthic organisms by 3D computer modelling, Methods Ecol. Evol., 6, 521-531, https://doi.org/10.1111/2041-210X.12331, 2015.

Livesley, S. J., Grover, S., Hutley, L. B., Jamali, H., ButterbachBahl, K., Fest, B., Beringer, J., and Arndt, S. K.: Seasonal variation and fire effects on $\mathrm{CH}_{4}, \mathrm{~N}_{2} \mathrm{O}$ and $\mathrm{CO}_{2}$ exchange in savanna soils of northern Australia, Agr. Forest Meteorol., 151, 1440 1452, https://doi.org/10.1016/j.agrformet.2011.02.001, 2011

Luxmoore, R. J.: Micro-, Meso-, and Macroporosity of Soil, Soil Sci. Soc. Am. J., 45, 671-672, https://doi.org/10.2136/sssaj1981.03615995004500030051x, 1981.

McKenzie, N., Jacquier, D., Isbell, R., and Brown, K.: Australian Soils and Landscapes?: an Illustrated Compendium, CSIRO Pub., 2004.

Noirot, C. and Darlington, J.: Termite nests: architecture, regulation and defence, in: Termites: evolution, sociality, symbioses, ecology, edited by: Abe, T., 121-139, Kluwer Academic Publishers, 2000.

Perna, A. and Theraulaz, G.: When social behaviour is moulded in clay: on growth and form of social insect nests, J. Exp. Biol., 220, 83-91, https://doi.org/10.1242/jeb.143347, 2017.

Perna, A., Jost, C., Couturier, E., Valverde, S., Douady, S., and Theraulaz, G.: The structure of gallery networks in the nests of termite Cubitermes spp. revealed by X-ray tomography, Naturwissenschaften, 95, 877-884, https://doi.org/10.1007/s00114-0080388-6, 2008.

R Development Core Team: R: A Language and Environment for Statistical Computing (3.4.0), R Foundation for Statistical Computing, Vienna, Austria, available at: http://www.R-project.org/ (last access: 14 June 2018), 2017.

Reichert, J., Backes, A. R., Schubert, P., and Wilke, T.: The power of $3 \mathrm{D}$ fractal dimensions for comparative shape and structural complexity analyses of irregularly shaped organisms, Methods Ecol. Evol., 2017, 1-9, https://doi.org/10.1111/2041210X.12829, 2017.

Saunois, M., Bousquet, P., Poulter, B., Peregon, A., Ciais, P., Canadell, J. G., Dlugokencky, E. J., Etiope, G., Bastviken, D., Houweling, S., Janssens-Maenhout, G., Tubiello, F. N., Castaldi, 
S., Jackson, R. B., Alexe, M., Arora, V. K., Beerling, D. J., Bergamaschi, P., Blake, D. R., Brailsford, G., Brovkin, V., Bruhwiler, L., Crevoisier, C., Crill, P., Covey, K., Curry, C., Frankenberg, C., Gedney, N., Höglund-Isaksson, L., Ishizawa, M., Ito, A., Joos, F., Kim, H.-S., Kleinen, T., Krummel, P., Lamarque, J.-F., Langenfelds, R., Locatelli, R., Machida, T., Maksyutov, S., McDonald, K. C., Marshall, J., Melton, J. R., Morino, I., Naik, V., O'Doherty, S., Parmentier, F.-J. W., Patra, P. K., Peng, C., Peng, S., Peters, G. P., Pison, I., Prigent, C., Prinn, R., Ramonet, M., Riley, W. J., Saito, M., Santini, M., Schroeder, R., Simpson, I. J., Spahni, R., Steele, P., Takizawa, A., Thornton, B. F., Tian, H., Tohjima, Y., Viovy, N., Voulgarakis, A., van Weele, M., van der Werf, G. R., Weiss, R., Wiedinmyer, C., Wilton, D. J., Wiltshire, A., Worthy, D., Wunch, D., Xu, X., Yoshida, Y., Zhang, B., Zhang, Z., and Zhu, Q.: The global methane budget 2000-2012, Earth Syst. Sci. Data, 8, 697-751, https://doi.org/10.5194/essd-8-697-2016, 2016.

Schindelin, J., Arganda-Carreras, I., Frise, E., Kaynig, V., Longair, M., Pietzsch, T., Preibisch, S., Rueden, C., Saalfeld, S., and Schmid, B.: Fiji: an open-source platform for biological-image analysis, Nat. Methods, 9, 676-682, 2012.

Schmidt, A. M., Jacklyn, P., and Korb, J.: "Magnetic" termite mounds: Is their unique shape an adaptation to facilitate gas exchange and improve food storage?, Insect. Soc., 61, 41-49, https://doi.org/10.1007/s00040-013-0322-6, 2014.

Seiler, W., Conrad, R., and Scharffe, D.: Field studies of methane emission from termite nests into the atmosphere and measurements of methane uptake by tropical soils, J. Atmos. Chem., 1, 171-186, https://doi.org/10.1007/BF00053839, 1984.
Stewart, R. D., Abou Najm, M. R., Rupp, D. E., and Selker, J. S.: An Image-Based Method for Determining Bulk Density and the Soil Shrinkage Curve, Soil Sci. Soc. Am. J., 76, 1217, https://doi.org/10.2136/sssaj2011.0276n, 2012.

Sugimoto, A., Inoue, T., Kirtibutr, N., and Abe, T.: Methane oxidation by termite mounds estimated by the carbon isotopic composition of methane, Global Biogeochem. Cy., 12, 595-605, https://doi.org/10.1029/98GB02266, 1998.

Turner, J. S.: On the mound of Macrotermes michaelseni as an organ of respiratory gas exchange, Physiol. Biochem. Zool., 74, 798822, https://doi.org/10.1086/323990, 2001.

Turner, J. S. and Soar, R. C.: Beyond biomimicry: What termites can tell us about realizing the living building, in: First International Conference on Industrialized, Intelligent Construction (I3CON), 14-16, Loughborough University, Leicestershire, UK, 2008.

Verhoeven, G.: Software Review - Taking Computer Vision Aloft Archaeological Three-dimensional Reconstructions from Aerial Photographs with PhotoScan, Archaeol. Prospect., 18, 67-73, https://doi.org/10.1002/arp.399, 2011.

Wenzel, K., Rothermel, M., Fritsch, D., and Haala, N.: Image Acquisition and Model Selection for MultiView Stereo, ISPRS - Int. Arch. Photogramm. Remote Sens. Spat. Inf. Sci., XL-5/W1(February), 251-258, https://doi.org/10.5194/isprsarchives-XL-5-W1-251-2013, 2013.

Zachariah, N., Das, A., Murthy, T. G., and Borges, R. M.: Building mud castles: a perspective from brick-laying termites, Sci. Rep., 7, 4692, https://doi.org/10.1038/s41598-017-04295-3, 2017. 